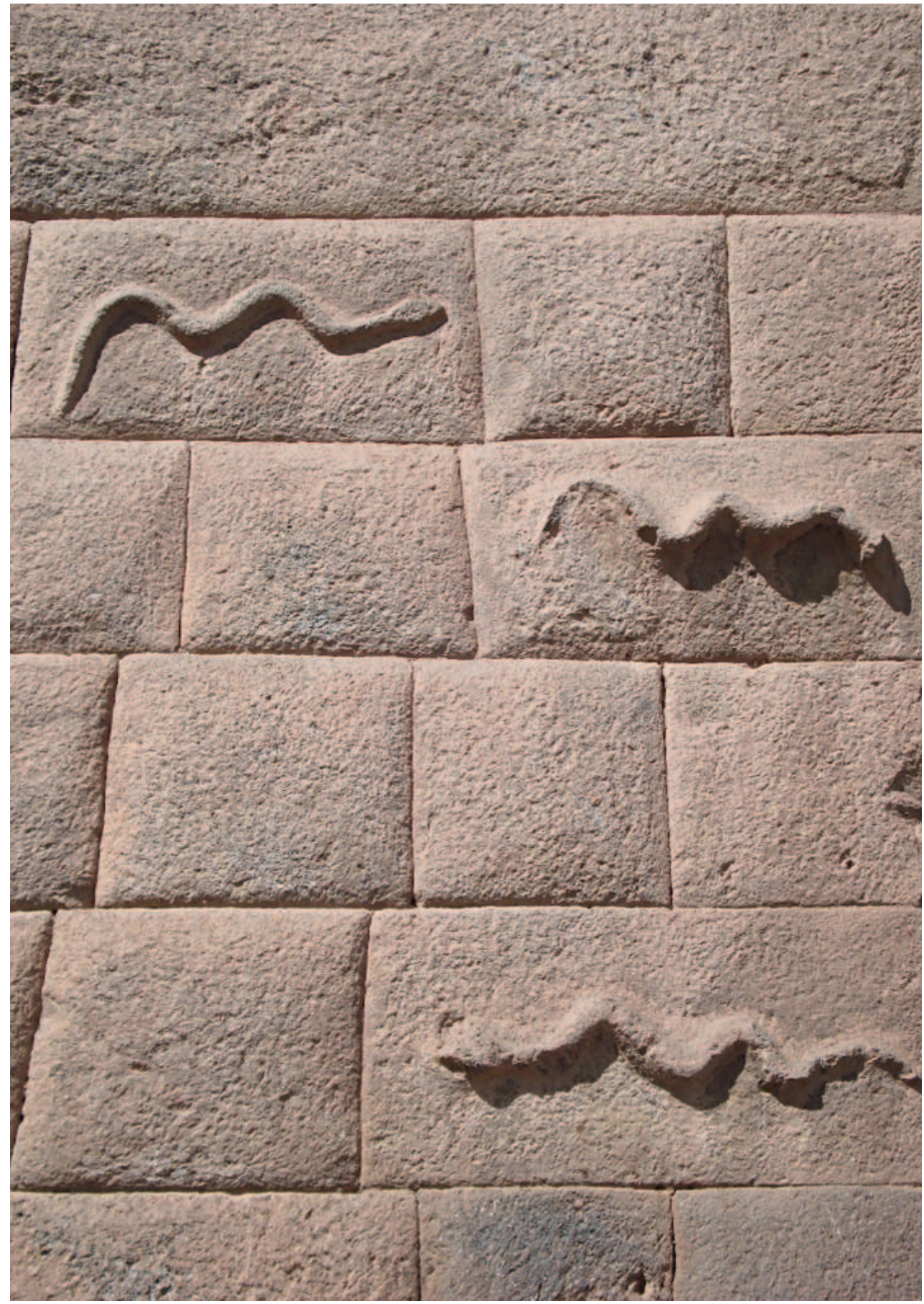




\title{
Petroglifos serpentiformes en la ciudad del Cusco. Contribución para el estudio de la plástica rupestre colonial
}

Manuel Munive Maco

\begin{abstract}
I. Introducción
Clasificables dentro de lo escultórico por tratarse de relieves pero desatendidos como tales al estar, aparentemente, "decorando" las fachadas y muros de algunos edificios del Cusco colonial, el estudio de estos petroglifos y sus variantes ha sido postergado hasta fechas muy recientes. ${ }^{1}$
\end{abstract}

Durante sucesivos viajes al Cusco entre el 2007 y el 2009 empezamos a familiarizarnos con las "culebras" que hallábamos labradas e incisas sobre algunos de los bloques pétreos que conforman los paramentos de varios edificios, principalmente coloniales, de su centro histórico. Aunque estos petroglifos pueden distinguirse a simple vista son inadvertidos por el turista común quien anda apremiado por confrontar la espectacularidad de lugares como Ollantaytambo o Machu Picchu. Es como si las expresiones plásticas rupestres que se encuentran en las calles céntricas de una ciudad cosmopolita como el Cusco se hallasen "mentalmente" más confinadas que aquellas otras situadas en parajes remotos e inhóspitos.

Resulta paradójico que la fotografía de Martín Chambi que insertamos como la primera ilustración de este trabajo [Fig.1] sea específicamente la responsable de que su redacción haya sido pospuesta varios años ya que, en lugar de proporcionarnos certezas para empezar a hablar de algunos de sus petroglifos serpentiformes sembró la duda acerca de la autenticidad de sus ubicaciones: al cotejarla con una fotografía actual del mismo edificio -sede del "Museo Inka" de la Universidad San Antonio Abad-descubrimos que el frontis ha sufrido cierta alteración detectable en una sutil reubicación de los bloques de piedra que

1 Después de haberle escuchado disertar sobre las "categorías del arte rupestre peruano" contactamos al arqueólogo Gori Tumi para consultarle sobre la bibliografía actualizada relacionada con estos petroglifos. La sorpresa fue doble al enterarnos que no sólo existía un artículo reciente -del 2010- sobre el tema y que estaba ilustrado por algunos de los especímenes que habíamos elegido sino que le pertenecía. Después de dudar sobre el sentido de escribir este trabajo -y por sugerencia del propio Tumi- decidimos terminarlo pero centrándonos en las serpientes. 


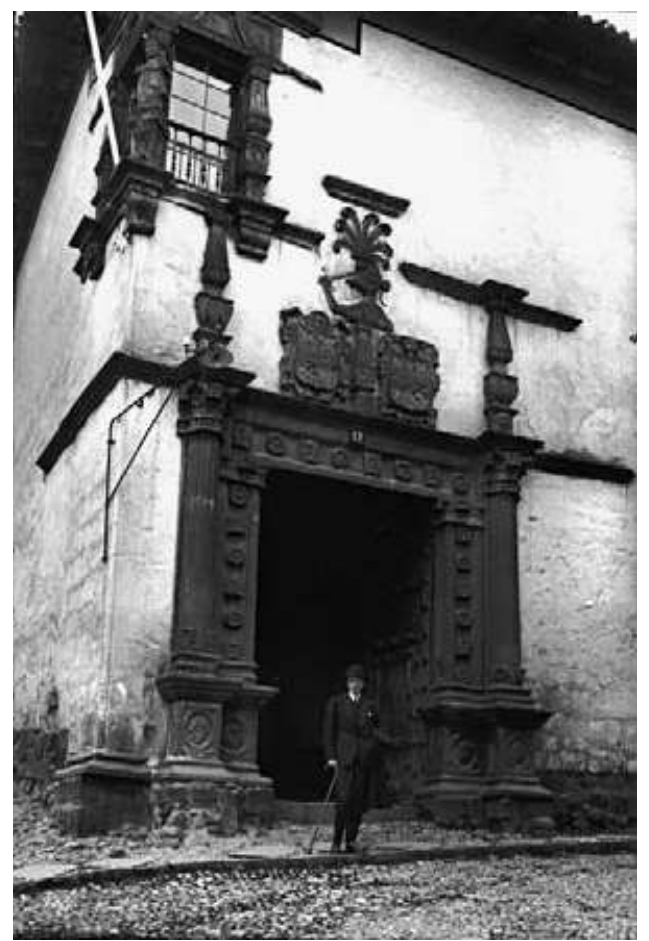

Fig.1. Casa del Almirante. Fotografía: Martín Chambi, ca. década de los años cuarenta. Cortesía Herman Schwarz.

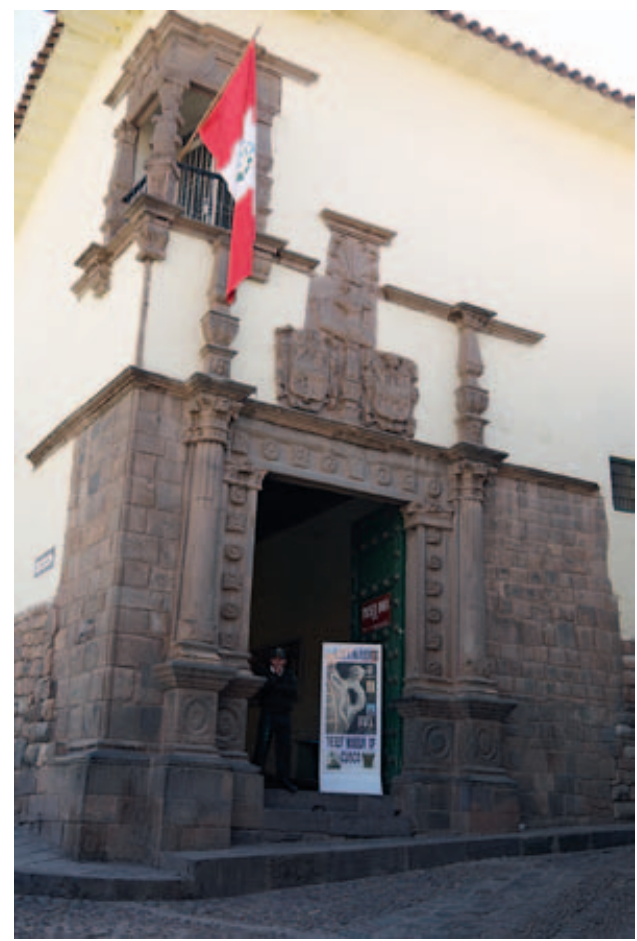

Fig.2. Museo Inka de la Universidad San Antonio Abad. Fotografía: José Luis Carranza.

flanquean su pórtico y, sobre todo, en el aparente cambio del nivel de la calzada. [Fig.2] Los primeros petroglifos que reconocimos entonces -exceptuando, desde luego, aquellos que proliferan en la calle "Siete Culebras", cuya celebridad también parece atentar contra una atención más cuidadosa de su complejidad iconográfica² ${ }^{2}$ se encuentran precisamente en un bloque del "zócalo" derecho de esta portada. [Figs.3 y 4]

Aunque no podemos ser categóricos la fotografía de Chambi nos induce a pensar que este par de serpientes pudo no estar en ese mismo lugar cuando ejecutó la toma. Y si ésta fue realizada con anterioridad al terremoto de 1950, lo que parece más probable, entonces comprenderemos dichas alteraciones y consideraremos que debemos dejar abierta la posibilidad de que algunos de los bloques con petroglifos pudieron provenir de otros lugares, tanto de una ubicación distinta en el mismo paramento o, a lo mejor, del paramento de algún otro edificio cercano. En el caso concreto del bloque que contiene este par de petroglifos se halla tan cercano al nivel del suelo que esta ubicación lo expone a reacomodos, no siempre adecuados, como la renovación de la calzada o del alcantarillado, por ejemplo. Es fácil percatarse de que este bloque ha sido embutido sin mucha precisión y que quien lo hizo tuvo que servirse de pequeñas lajas a manera de cuñas para fijarlo.

Pero la fotografía de Chambi ofrece información adicional sobre la aparente escasa importancia que en el Cusco de entonces se daba a las fachadas antiguas: el aparejo de piedra "nativo" que flanquea el pórtico "español" del edificio -en el cruce de la Cuesta del Almirante y la calle "Ataúd"3- aparece cuidadosamente pintado de blanco, "silenciado",

2 Es fácil constatar que hay más de siete “culebras" e incluso otro petroglifo muy peculiar que representa un ser antropomorfo con un báculo.

3 Castellanización de la palabra quechua “Atau”, “Macho de ave” según Valcárcel (1945). 

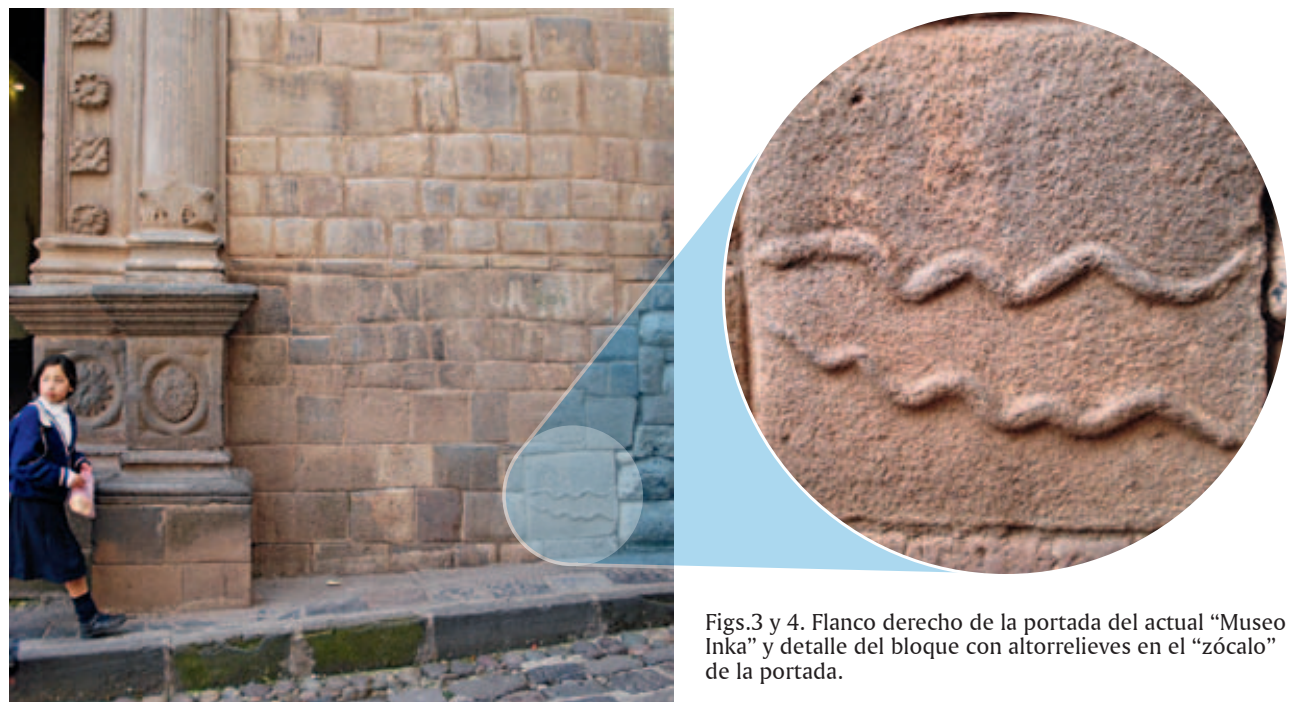

Figs.3 y 4. Flanco derecho de la portada del actual "Museo Inka" y detalle del bloque con altorrelieves en el "zócalo" de la portada.

tal como parece haber hecho consigo mismo el individuo cusqueño que vestido como un "personaje inglés" 4 posa ante el lente de Chambi. Esta práctica, a la vez, puede explicar el que algunos de los petroglifos que revisaremos, fundamentalmente altorrelieves ${ }^{5}$, luzcan parcialmente "borrados". Cubrirlos con pintura o rasparlos forma parte de una misma actitud que podría haberse iniciado inmediatamente después de la insurrección de Túpac Amaru (1780), cuando el gobierno español proscribe muchas de las prácticas culturales de la nobleza incaica.

Si toda ciudad es un escenario en constante metamorfosis, en el caso del Cusco, paradigma de la violenta superposición de una cultura sobre otra y de una transformación agravada por grandes sismos -al menos dos terremotos en trescientos años- hacer un análisis tentativo de la simbología de los petroglifos diseminados por sus callejas tomando como punto de partida su ubicación en el espacio urbano se presenta como algo difícilmente viable. Obstáculos similares debe enfrentar quien decida indagar acerca de la lógica que rige la distribución de las serpientes sobre los muros y vanos. (Por eso descartamos nuestra idea inicial de establecer una probable relación entre la distribución de los petroglifos en una fachada, la ubicación de ésta en el plano de la ciudad y las coordenadas de los ceques incas).

\section{La serpiente y su significado para el mundo andino}

“...tres símbolos son constantes en la cultura andina (...). Estos (...) son el ofidio y el felino, el tercero es el ave (cóndor, águila, halcón). La sierpe de una sola cabeza (...) es símbolo del agua, del rayo, del trueno, del relámpago, de la lluvia, del río. La sierpe celeste se identifica con Illapa, el Rayo-Dios, es la serpiente luminosa que alumbra el mundo en la noche de la tempestad, en el día nublado y que anuncia la esperada y bienhechora agua del cielo. Es también Mama-Yacu o la madre del agua”. (Valcárcel, 1959: 14)

Representado plásticamente sobre una gran diversidad de soportes a lo largo de milenios por todas las sociedades andinas desde Chavín hasta los Incas el ofidio parece culminar su

4 Este y muchos otros títulos de las fotografías de Chambi -como seguramente sucedió con las de otros artífices de la primera mitad del siglo XX- fueron asignados a partir de la "anécdota" representada en la imagen. Por ello es necesario tomarlos solamente como una referencia inicial.

5 Aunque todos los petroglifos que hemos visto son altorrelieves es probable que existan otros incisos. 


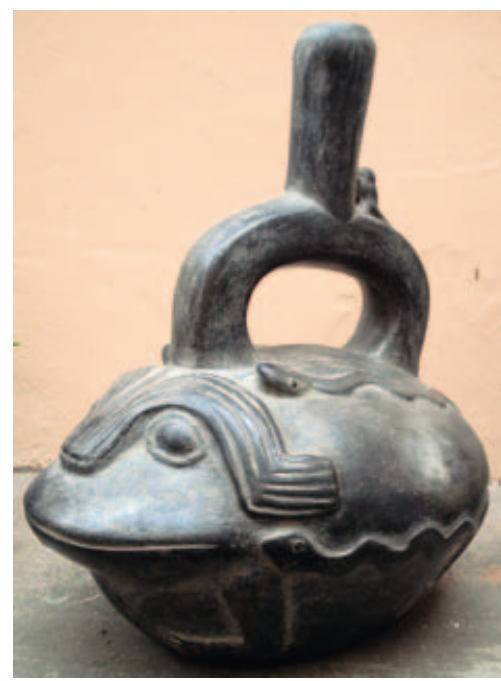

Fig.5. Ceramio Chimú que representa batracio con cuatro serpientes.

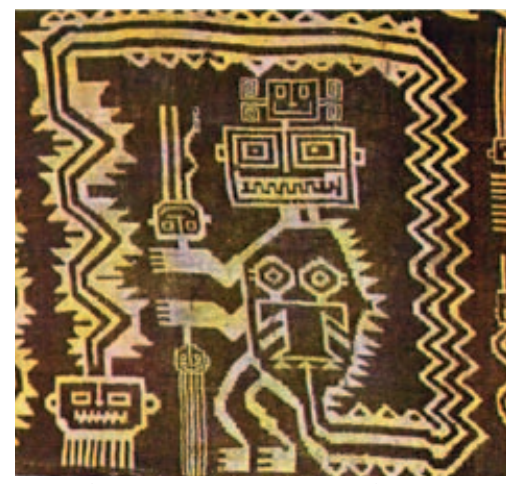

Fig.6. Manto Paracas. Personaje "con cuerpo terminado en una serpiente". Arte precolombino, Banco de Crédito, 1977.

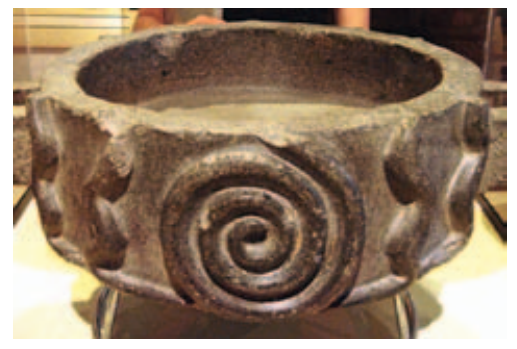

Fig.7. Paccha lítica inca con representación del "ofidio de la lluvia". MNAAHP.

periplo iconográfico en los altorrelieves serpentiformes que venimos mencionando.

Entre todas sus significaciones predomina fundamentalmente aquella referida a su vinculación con el agua que discurre y con la fecundidad y la vida que ésta, tanto en la lluvia y en el caudal de los ríos, propicia. Esa movilidad del agua y su irrupción violenta como elemento fecundante le confiere su carácter masculino $\mathrm{y}$, por complementariedad, las quietas aguas de lagunas y manantiales, se asocian con lo femenino.

Hallamos con facilidad ejemplos de serpientes pintadas y modeladas sobre vasijas cerámicas [Fig.5]; pintadas y bordadas sobre tapices y otros especímenes textiles [Fig.6]; labradas sobre artefactos líticos -como en aquellos que sirvieron de pacchas- [Fig.7] así como pintadas sobre keros, aunque en estos cuencos de madera para libaciones rituales, las culebras presentan hasta dos aspectos: inicialmente serán representadas con cierto naturalismo [Fig.8] o con dos cabezas, una a cada extremo, cuando simbolice al arco iris, mientras que, posteriormente, en los keros de transición, esta serpiente tendrá alas y patas con garras, cual un dragón, criatura concebida ya por la ideología de la nobleza cusqueña durante el periodo denominado del Renacimiento Inca. Abundantes son también aquellos petroglifos más esquemáticos o sintéticos que se asocian a primera vista con serpientes por consistir, básicamente, en incisiones sinuosas pero que bien podrían aludir a otros conceptos, como los que encontramos en diversos sectores cercanos al atrio de la iglesia de Chinchero. [Fig.9]

Las "serpientes" labradas que vamos a revisar aquí se asemejan formalmente a las representaciones más arcaicas aun cuando parecen haber sido hechas en el período transicional (s. XVI). Una mirada rápida sobre los diversos aparejos del Cusco nos lleva a concluir, por lo menos, que estas serpientes no proliferaron sobre los muros de piedra durante el Tahuantinsuyu y que, por el contrario, tendieron a representarse, recién, en la arquitectura mestiza o erigida por manos nativas, específicamente después del incendio del Cusco en 1535. ¿Por qué ocurre esto? ¿Será porque los muros de piedra, al contrario de lo que sucede con los ceramios, textiles, metales y objetos líticos, ofrecían una garantía de mayor perdurabilidad y sobre todo un "anclaje" simbólico en el espacio urbano? Y ¿por qué se prefirió labrar allí esas serpientes y no otras criaturas del bestiario mítico del Perú antiguo?

Aquí conviene mencionar que el repertorio de petroglifos sobre los muros de piedra de la capital inca es diverso. En vista de que existe un trabajo reciente que ha clasificado estas 
expresiones rupestres, ${ }^{6}$ hemos preferido concentrarnos únicamente en las serpientes o amarus y porque éstas, a diferencia de los petroglifos geométricos incisos, sí fueron tratados en altorrelieve. Esta característica, que requiere de un conocimiento más especializado por parte de su artífice, puede servirnos para diferenciar una expresión plástica de una auténtica pieza de "arte". Usualmente se incurre en el equívoco de denominar arte a todos los especímenes plásticos rupestres.

Lo cierto es que, a excepción de aquellos petroglifos en la portada del Beaterio de las Nazarenas que veremos más adelante, estas intervenciones no parecen haber sido hechas con el propósito de "decorar" u "ornamentar" sino que, por el contrario, aparentan ser elementos simbólicos, algunos no muy visibles y otros subrepticios o imperceptibles para una mirada culturalmente ajena.

\section{La serpiente o Amaru en el Cusco colonial}

Al considerar la posibilidad de que los muros hayan sufrido alteraciones y los bloques de piedra reubicaciones y desplazamientos durante la intensa historia urbana del Cusco proponemos aquí una primera aproximación a los petroglifos serpentiformes basada en un análisis de su morfología: aislando cada bloque que los contenga, familiarizándonos con sus diseños y estableciendo un breve repertorio iconográfico. En segunda instancia, dedicaremos especial atención a aquellos petroglifos plasmados en bloques de piedra que por su disposición en los edificios -ya sea conformando estructuralmente una jamba o una esquina, por ejemplo- nos dan la seguridad de que estuvieron allí desde el principio.

\section{III. a. Aspectos técnicos}

Las serpientes en altorrelieve se encuentran todas sobre soportes de piedras diversas, en la mayoría de casos, andesita -tal como la usada en la época Inca Imperial (1438-1533) - así como diorita y caliza. Sus dimensiones son similares y fluctúan entre los 28 y 50 $\mathrm{cm}$. de longitud aunque hay algunas que exceden el metro. [Fig.22] Sus ubicaciones sobre el paramento son muy variables: pueden estar a la altura de los ojos del viandante o a varios metros sobre él, es decir, hasta en la última hilada de bloques. El labrado por percusión fue aparentemente la técnica básica. Algunas de las serpientes, particularmente las más elevadas, parecen haber quedado esbozadas y nos ilustran sobre el proceso de ejecución.

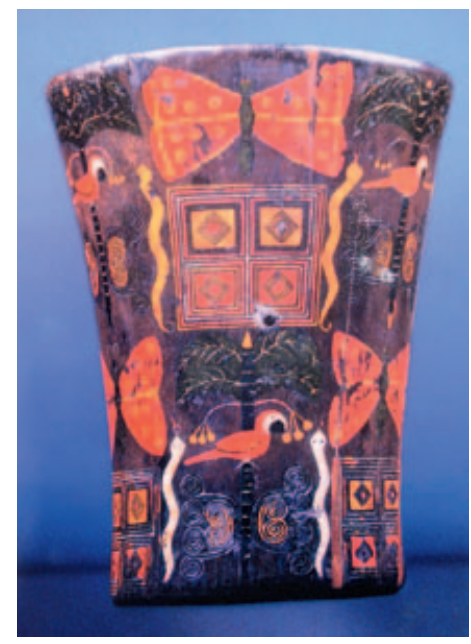

Fig.8. Kero. Siglo XVIII. Col. "Museo Inka", Cusco. Tomado del libro Keros, Banco de Crédito.

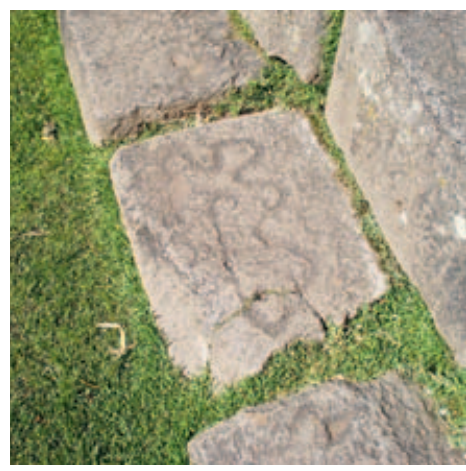

Fig.9. Petroglifos incisos sobre escalones. Cruz atrial en Chincheros, Cusco.

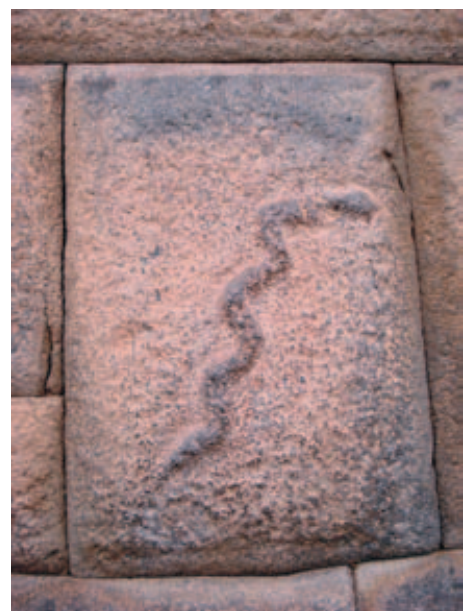

Fig.10: Petroglifo sobre bloque pétreo en paramento de la Plaza Nazarenas.

6 TUMI, Gori et al. Las cuatro tradiciones del arte rupestre colonial del Cusco. En: Quellca Rumi. Revista de investigaciones de la Asociación Peruana de Arte Rupestre (APAR). Volumen 1, No. 1. Diciembre, 2010. 


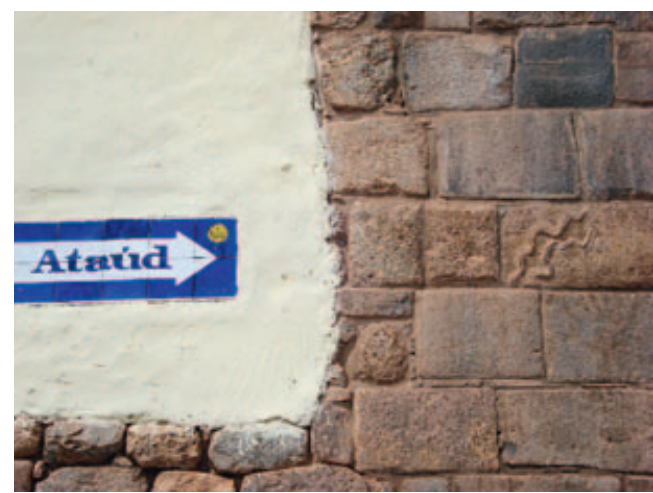

Fig.11: Petroglifos en la calle Ataúd.

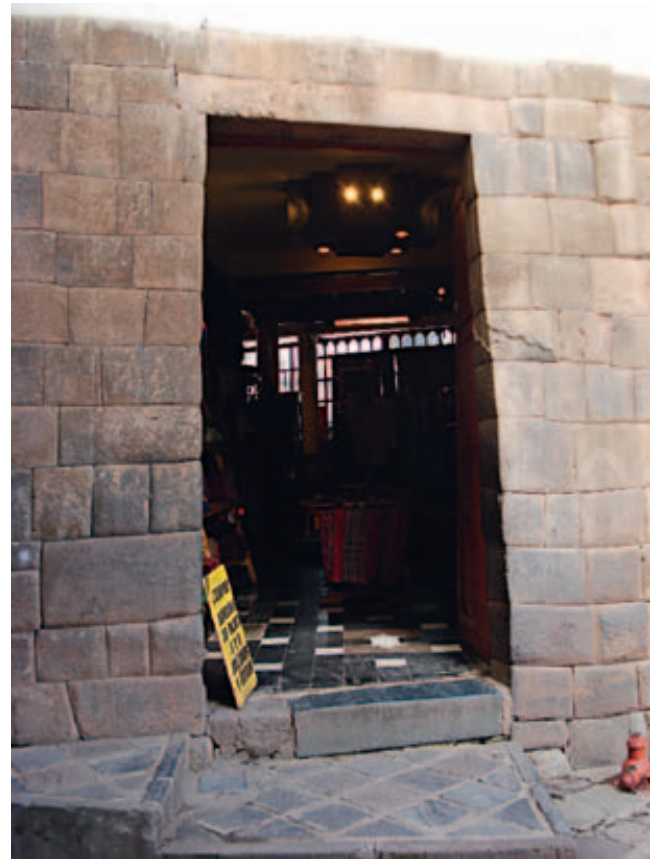

Fig.12: Pórtico inca con petroglifos frente al "Museo Inka”.

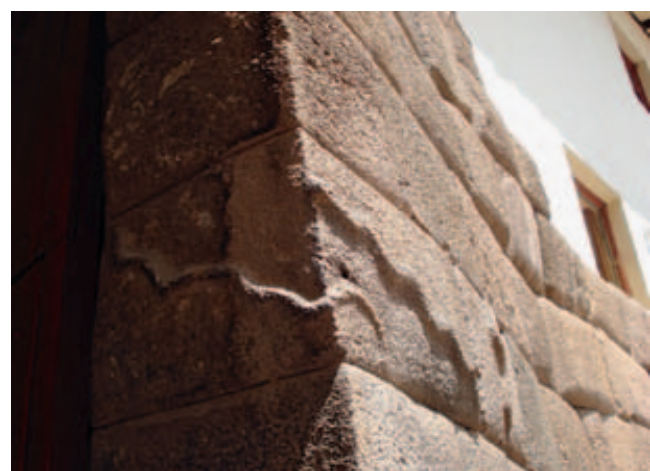

Fig.13. Petroglifos sobre bloque en jamba.

\section{III. b. Tipología formal}

Las serpientes representadas individualmente en un bloque pueden "orientarse" hacia cualquier dirección. Y si colindan con otras que están en bloques adyacentes pueden tener o no una "vinculación" aunque esta apreciación es de extrema subjetividad por parte del espectador contemporáneo. (Por ejemplo, una de ellas en la esquina de la Nazarenas y Siete culebras parece descender directamente hacia otra que se halla varios bloques más abajo y que también la "mira").

Cuando dos serpientes aparecen en un mismo bloque suelen dirigirse hacia la misma dirección o hacia sentidos opuestos, una hacia la derecha y la otra hacia la izquierda o hacia arriba y hacia abajo.

Para instruirnos acerca de la calidad de labrado original contamos, "por suerte", con los amarus realizados con fines decorativos en algunas edificaciones modernas del Cusco revestidas de piedra así como sus falsificaciones en muros relativamente antiguos como el que existe en la calle Santa Catalina Ancha. Lamentablemente se pueden notar también algunos casos en los que los amarus originales han sufrido los intentos de "rebajarlos" como la serpiente de la jamba derecha en la edificación de la calle Zetas que también comentaremos un poco más adelante. (Por otro lado, también parece que algunos petroglifos fueron "repasados" alterando la impronta original aunque eso suele ser más frecuente con los petroglifos no-figurativos, es decir, incisos o en bajorrelieve que se hallan sobre el plano horizontal ya sea en el suelo o sobre el "paso" de una escalinata).

Tomando en cuenta una clasificación de los petroglifos en altorrelieve trabajados en cada bloque hallamos dos variantes:

I. Una sola serpiente. (Esta puede estar "en tránsito hacia cualquier dirección" o puede estar enroscada en sí misma). [Fig.10]

II. Dos serpientes que se relacionan entre sí. A su vez esta variante puede dividirse en: 


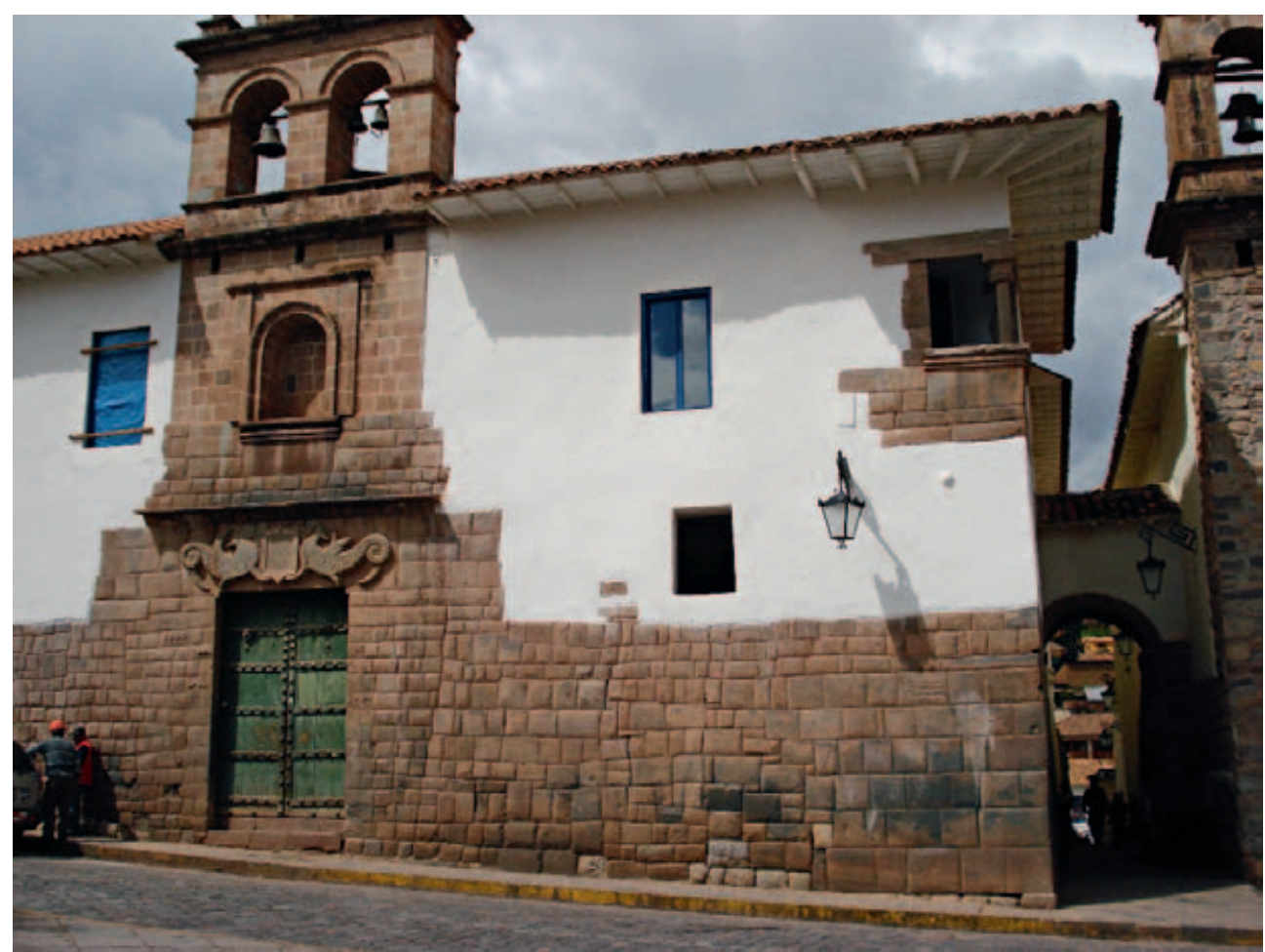

Fig.14. Plaza y Beaterio de las Nazarenas.

a. Serpientes pareadas en desplazamiento de "ida y vuelta" [Fig.4];

b. Serpientes pareadas que se dirigen hacia un vano [Fig.21] y

c. Serpientes que ingresan a un edificio. [Fig.13]

\section{III. c. Repertorio de petroglifos analizados}

Los conjuntos de petroglifos sobre los que nos detendremos brevemente se encuentran fundamentalmente en tres sectores del casco histórico:

1. En el entorno de la portada del actual Museo Inka.

2. En la Plaza de las Nazarenas, en dos secciones vinculadas por un petroglifo serpentiforme de singular diseño y ubicación.

3. En la calle que está frente a la Plaza Limacpampa

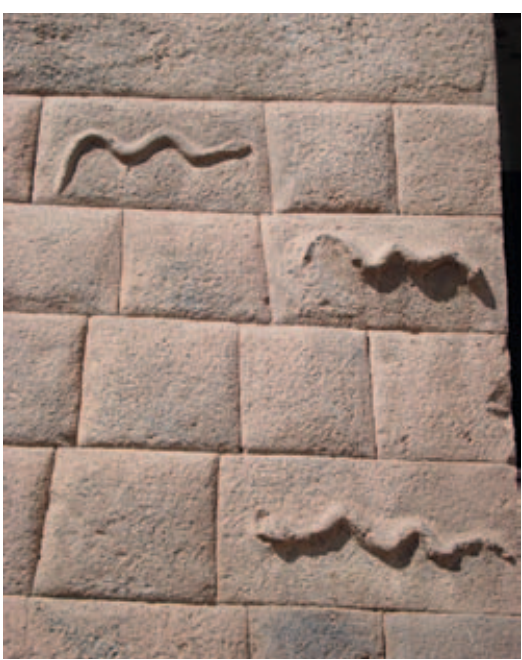

Fig.15 Petroglifos en flanco izquierdo del pórtico del Beaterio. y desemboca en la fachada de la Iglesia de Santo Domingo, cuyos tramos reciben los nombres de Zetas y Abracitos.

Primer sector:

Hallamos dos bloques con petroglifos en el perímetro del Museo Inka: el que mencionamos al inicio de este escrito en el zócalo del pórtico de ingreso, que contiene dos serpientes que se dirigen, horizontalmente, hacia la izquierda y la derecha. Esta distinción es posible 


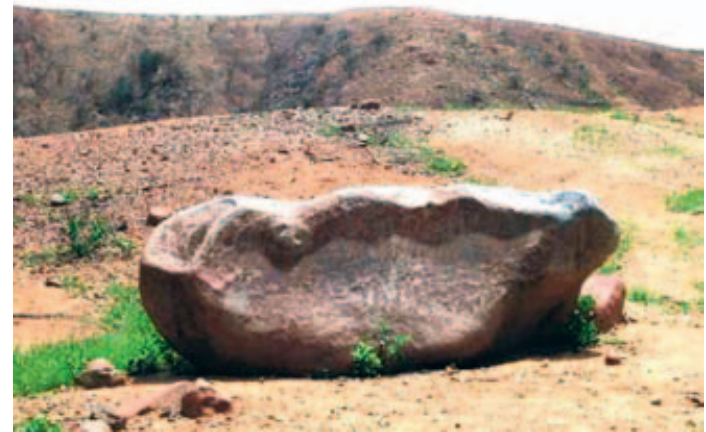

Fig.16. Serpiente en paccha lítica en el Alto de las Guitarras, Trujillo. Fotografía: Cristóbal Campana.

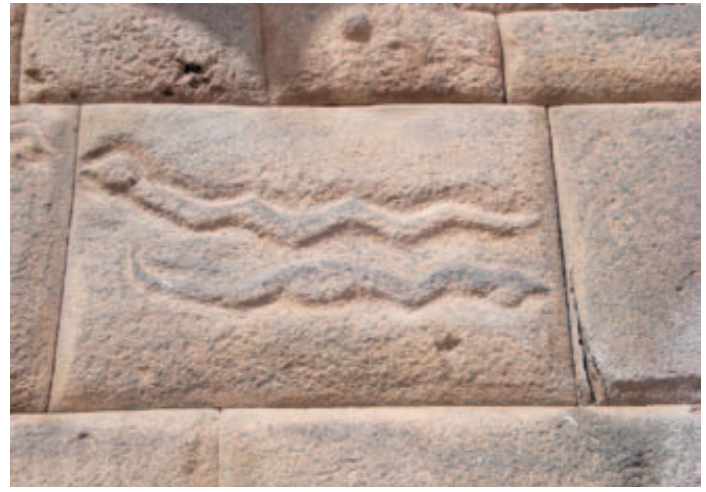

Fig.17: Serpientes con "pico" en paramento del Beaterio de las Nazarenas.

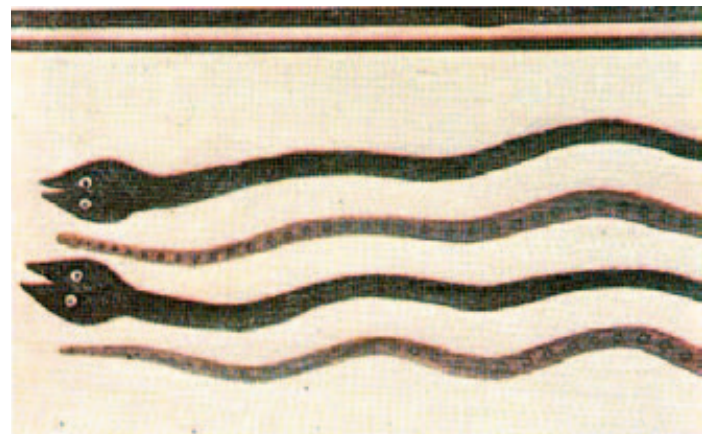

Fig.18. Acuarela. "Dos tipos de culebras en posición horizontal en posiciones opuestas". Tomado del libro de J. Fernández Baca,

“Motivos de ornamentación de la cerámica inca, Cusco", 1989. gracias a la diferenciación plástica entre la cabeza y la cola. [Fig.4] El segundo bloque, a unos tres metros sobre el nivel del suelo y al costado izquierdo del edificio -casi al mismo nivel del cartel con el nombre de la callecontiene dos serpientes ondulantes que parecen moverse diagonalmente. Estas últimas son prácticamente imposibles de distinguir en la fotografía de Chambi pues están en el sector que allí aparece completamente encalado. [Fig.11]

Prácticamente frente a la portada del "Museo Inka" encontramos un pórtico muy valioso por ser trapezoidal y porque tiene en la jamba derecha un bloque con petroglifos realmente singulares: ambas serpientes se dirigen hacia el interior del recinto. Una está introduciendo la cabeza mientras la otra lo hizo casi por completo, dejando en el plano exterior únicamente un extremo de su cola. Hacia la derecha colinda con un bloque menos rectangular en el que una serpiente dispuesta verticalmente parece ascender, y hacia la jamba opuesta, más arriba, existe un bloque cuadrado cruzado por otra serpiente que asciende diagonalmente. [Fig.12 y 13]

\section{Segundo sector:}

Esta se halla más arriba -prácticamente a la espalda de la Catedral y aproximadamente a dos minutos de caminata de la anterior- y está constituida por la fachada del Beaterio de las Nazarenas, compuesta por su portada y el tramo que corre hasta la calle Siete Culebras. [Fig.14] El despliegue relativamente numeroso de petroglifos, en su mayoría serpentiformes, son indicativos de su importancia como espacio ritual.

Flanqueando el lado izquierdo de la portada del Beaterio encontramos los que consideramos los amarus mejor elaborados considerando su "naturalismo". En verdad, su modelado evoca la sinuosidad de los ofidios al desplazarse. Lamentablemente estos parecen haber sufrido algún tipo de maltrato de antigua data. Su calidad se manifiesta al compulsarlo con otro petroglifo serpentiforme de factura comparativamente posterior en el mismo sector. [Fig.15] También es probable que estos sean los altorrelieves más pronunciados con respecto al plano del bloque y como tales requirieron de un modelado o esculpido. Como ya lo mencionamos, las incisiones, aun cuando implican un tratamiento que permita evocar el zigzagueo del ofidio no requieren sin embargo de una pericia cabalmente escultórica. 
(Comparemos el efecto de la sombra en las serpientes del lado izquierdo con el efecto semejante de la serpiente escultórica que se puede reconocer hacia el mediodía en la enorme paccha que encontramos en el emporio rupestre de El Alto de las Guitarras, en Trujillo [Fig.16]). También aporta información valiosa sobre su realización el que comparemos el "naturalismo" de estos amarus con el esquematismo extremo y la rigidez con que fueron trabajados los tritones que sobre el dintel portan el escudo).

Sobre las funciones que durante el incario se realizaban en este lugar Valcárcel refiere:

"Muy pocos cronistas hacen referencia a las academias o escuelas incaicas. Sabemos que existieron por lo que nos cuenta, sobre todo, Garcilaso. (...) Las escuelas ocupaban los recintos de piedra que constituyen en el día el recogimiento o beaterio de las Nazarenas. En sus muros hay un buen número de alto relieves con representaciones totémicas del Amaru y una suerte de raposa, aún no identificada”. (Valcárcel, 1945: 169 - 170)

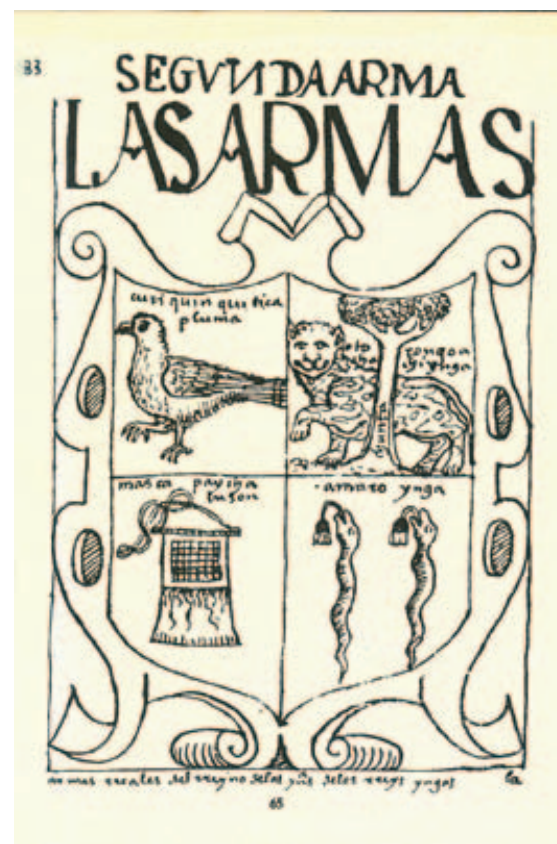

Fig.19. “Segunda arma...”. Lámina 83 de la Nueva coronica de Guaman Poma de Ayala.

No podemos estar seguros de que se trate de una "raposa”. Sin embargo, podemos decir que se trata de un animal cuadrúpedo con cola, muy toscamente esbozado. ¿O era así como se empezaba a desbastar la piedra hasta ir modelando las figuras? El que muchos de los bloques presenten un "almohadillado" facilitaba el labrado de los petroglifos pues básicamente había que "excavar" en torno al diseño trazado. A la vez esto evidenciaría que era posible trabajar los petroglifos sobre los bloques que estaban ya afincados a un paramento.

La supervivencia de estas “culebras” nos induce a hacer otras conjeturas: ¿Por qué no fueron borradas como seguramente sucedió con muchas otras durante la censura de imágenes nativas a fines del siglo XVIII? ¿Porque al ser la portada de una "Casa del Saber" pudo estar a salvo de dicha purga icónica? ¿Y si estos petroglifos fueron labrados con posterioridad a ese acontecimiento y resultan ser menos antiguos de lo que suponemos? El que en sus inmediaciones subsista un pasaje con tantas serpientes labradas no pudo ser casual.

Hallamos sobre otros bloques del mismo muro algunas serpientes que tienen una característica peculiar: al menos tres de ellas presentan una suerte de "pico" en el extremo de la cabeza, detalle que nos hizo pensar que se trataba de especímenes inconclusos. Sin embargo, existe evidencia de una variante iconográfica en la que ese pico podía representarse “abierto”. Así lo demuestra una de las ilustraciones arqueológicas preparadas por Fernández Baca a partir de su transcripción del

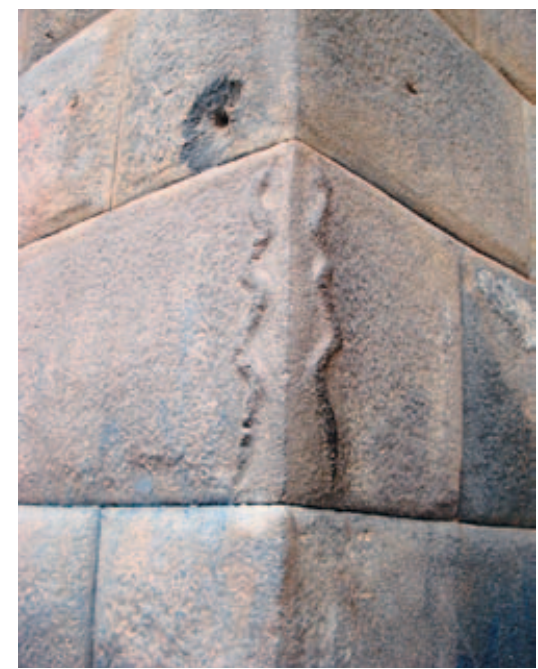

Fig.20. Petroglifos idénticos en bloque esquinero de la calle "Siete Culebras". 


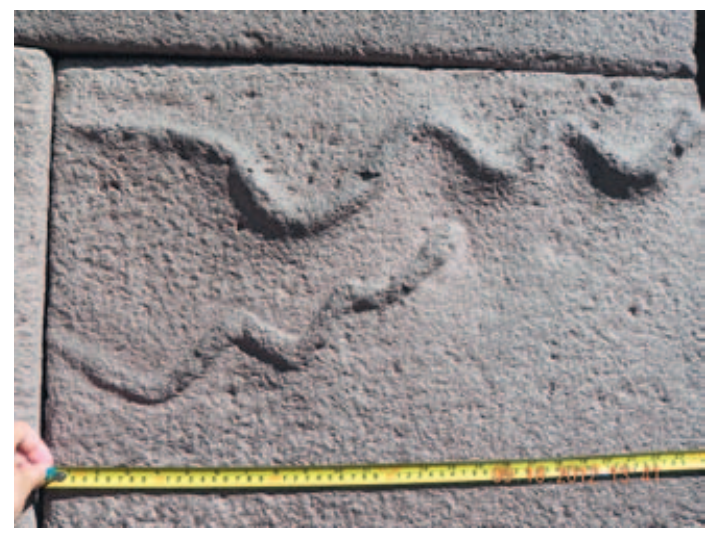

Fig.21. Petroglifos que se dirige hacia pórtico en Calle Zetas. Fotografía: Lic. Saby Zaldívar.

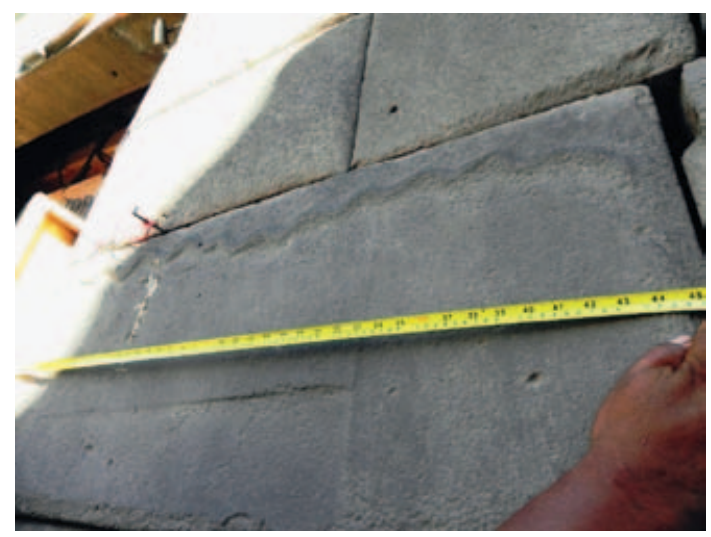

Fig.22. Petroglifo de más de un metro de longitud al lado derecho del mismo pórtico. Fotografía: Lic. Saby Zaldívar. diseño y el color de los fragmentos de la cerámica inca recolectada en las inmediaciones del Cusco. [Fig.17 y 18]

Dicho "pico" y "boca abierta" en las serpientes nos lleva a relacionarlas con aquellas dibujadas en la lámina 83 de la Nueva corónica y buen gobierno en donde vemos un escudo titulado "segunda arma", en el que Guaman Poma de Ayala incluye un ave -el corequenque-, un felino -el otorongo - y un par de serpientes "con unas borlas en la boca”. Aunque no se trate de borlas esa prolongación en la boca de las culebras analizadas pareciera indicar un significado que va más allá de la representación naturalista así como el hecho de su recurrencia al ser representadas en pares. [Fig.19] (Sobre la fauna inscrita en dicha lámina Luis Millones precisa que "el jaguar, dos serpientes y un picaflor ocupan tres de los cuatro cuarteles del mencionado escudo; y el cuarto espacio está tomado por la mascapaycha o borla que adornaba la cabeza del gobernante incaico y algunos miembros de la élite". (Millones, 2012: 84)

En la calle "Siete Culebras" se encuentran los petroglifos serpentiformes más celebrados. Sin embargo, no es conveniente disociarlos de aquellos otros que pueden rastrearse en el tramo que acabamos de mencionar. El que las serpientes no aparezcan más allá del sector donde empieza la actual reja que clausura la calle algunas noches nos lleva a pensar que esa zona cercana a la plaza y entre edificios originalmente religiosos -beaterio, iglesia y noviciado- fue un reducto particularmente propicio para la expresión rupestre concebida como una resistencia cultural sobre todo si recordamos que para la Iglesia el ofidio simbolizaba la encarnación del mal.

Lo que recalca esta importancia es aquel bloque pétreo situado en la esquina que contiene dos petroglifos serpentiformes gemelos pero cada uno en un lado distinto y colindante. El aparecer cada uno en una calle distinta convierte a este bloque en una especie de "bisagra" o "prolongación" sutil del muro del Beaterio y, a la vez, conecta de alguna manera los petroglifos de ambos lados. En ese sentido esta pieza es única y merecería un estudio aparte ya que podría revelar algunas pistas acerca de la concepción espacial andina. Tal vez sea importante señalar que están situados más o menos a la altura de los ojos de una persona de estatura alta. [Fig.20]

\section{Tercer sector:}

Conformada por un muro largo de notable aparejo sedimentario encontramos, distanciados uno del otro por algunos metros, dos conjuntos de amarus. Dos corren paralelos, en bloques superpuestos y colindantes, cercanos a la Plazuela Santo Domingo. Otro conjunto se halla en torno de un pórtico cuyo frente da ya a la Plaza Limacpampa: dos serpientes 


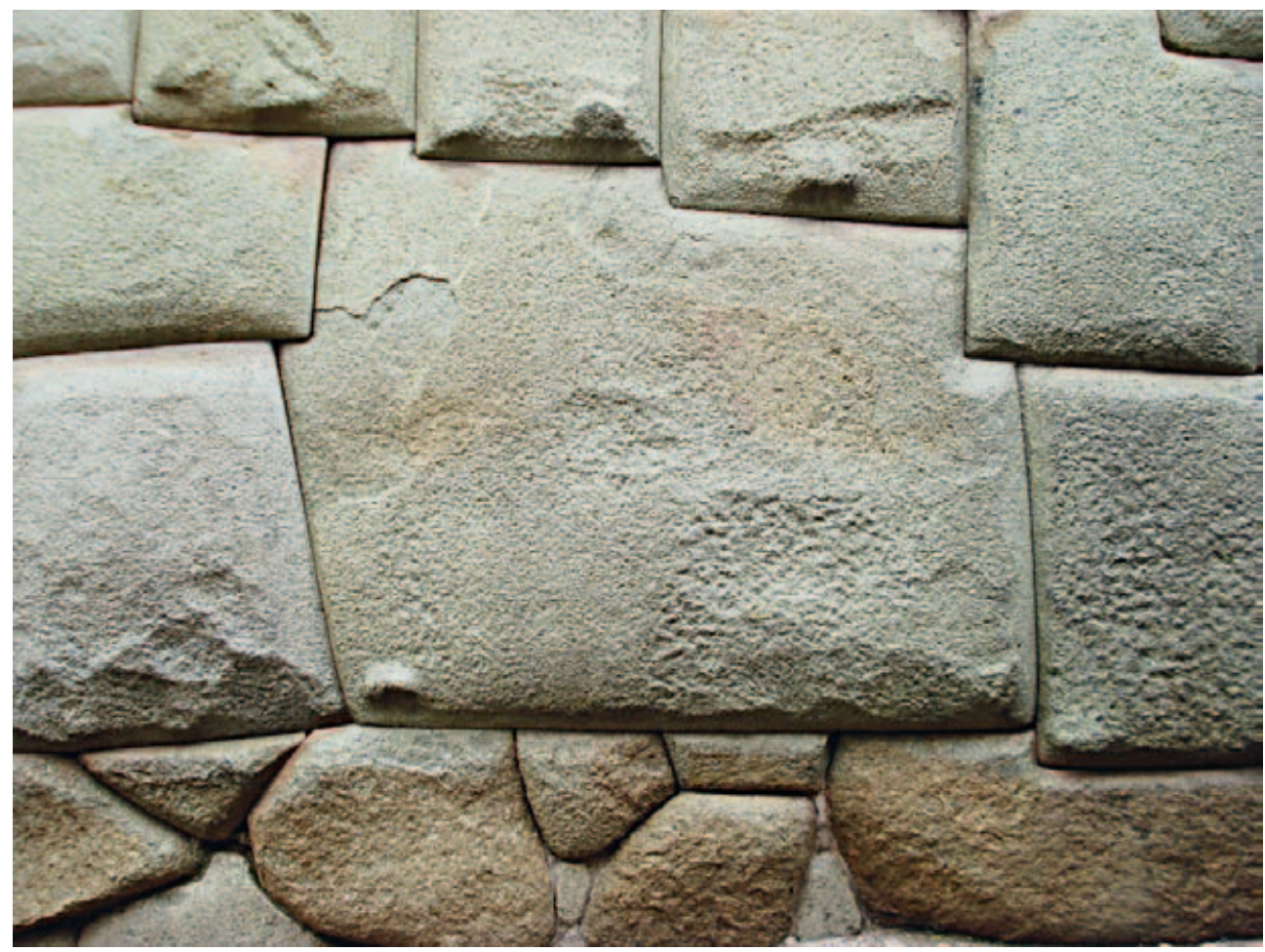

Fig.23. Piedra de los “Doce ángulos”, Hatunrumiyoc, Cusco.

se hallan en un mismo bloque hacia la jamba izquierda, dirigiéndose hacia el interior del edificio. [Fig.21] La inferior tiene menores dimensiones y podría interpretarse como la más joven y que, por eso sigue, algo rezagada, a la mayor. En un largo bloque rectangular de la jamba derecha vemos una serpiente cuya longitud sobrepasa el metro y permite contabilizar hasta trece curvaturas. Es la más larga de las que hemos podido fotografiar y la que muestra indicios de un sostenido intento por borrarla de la superficie. [Fig.22]

Afortunadamente esta construcción se halla documentada en el catastro que a fines de la década de los setenta dirigió Santiago Agurto. Su datación nos resulta útil pues sirve de referencia para situar cronológicamente al menos dos ejemplos más, nos referimos a aquellos que contienen serpientes que concurren hacia un pórtico y que mencionamos en el primer eje, situados frente al Museo Inka. Agurto clasifica este sitio como de "Transición”, entre 1533 y 1572, y estima que se trata de una vivienda ${ }^{7}$.

(Existe una sola culebra labrada en el fino paramento de la fachada del edificio donde actualmente funciona el Hotel Libertador como confirmando la idea de que éstas escasean sobre aparejos del periodo inca. De igual manera este muro y algunas perforaciones circulares perfectas en los bloques que conforman su esquina también inducen a hacer conjeturas sobre su significado).

7 Sobre sus características esenciales informa: "Muro de carga, de piedra, de aparejo sedimentario rectangular con una puerta de transición. El dintel de la puerta tiene un escudo en relieve y en las jambas hay tres serpientes en alto relieve". 


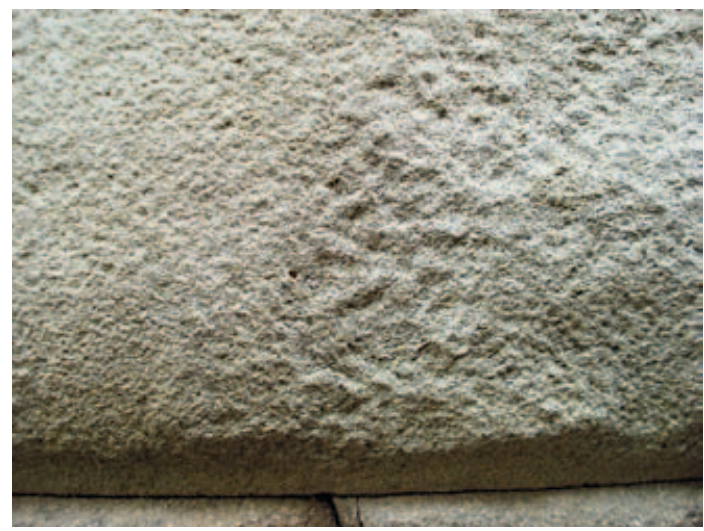

Fig.24. Detalle en piedra de los "Doce ángulos".
IV. ¿Una serpiente oculta en la Piedra de los Doce Ángulos?

La "Piedra de los Doce Ángulos" es una verdadera celebridad entre todas aquellas que constituyen el aparejo ciclópeo del Hatunrumiyoq o palacio de Inca Roca -hoy Palacio Arzobispal- y es la postal imprescindible que todo viajero desea llevar consigo. [Fig.23] Una inspección detenida nos llevó a identificar un diseño que, antes que un accidente de la piedra, parece haber sido labrado.

La imagen fotográfica más antigua de esta piedra le pertenece, una vez más, a Martín Chambi y data aproximadamente de la década de los años cuarenta. Al menos, desde entonces, la "Piedra de los Doce Ángulos" no parece haber sufrido alteraciones y en ella reconocemos también el diseño que mencionamos, una pequeñísima serpiente que se sitúa casi en el centro exacto de su base. [Fig.24] Un par de amigos que entienden del tema nos recomendaron publicarla ahora pues si bien no podemos atribuirle una total autenticidad, sin embargo, presenta indicios suficientes para un análisis posterior. De tratarse de un petroglifo estaríamos ante uno de los más diminutos especímenes de la plástica rupestre en el Cusco que parece haber sido dejado inconcluso antes que haber sido parcialmente borrado. Un análisis físico de ese sector de la piedra podría sacarnos de dudas al respecto. El extremo y hasta "fanatizado" cuidado que esa piedra recibe en la actualidad como consecuencia de los últimos atentados vandálicos de nacionales y extranjeros sobre el patrimonio arqueológico del Cusco impide tocarla e inspeccionarla a cualquier hora.

\section{A modo de conclusión provisoria}

Contamos con un buen número de petroglifos serpentiformes distribuidos en varias de las antiguas calles del centro histórico del Cusco que podrían proporcionar mayor información acerca de su origen, tanto en el aspecto técnico -tipos de piedra y herramientas usadascomo en el aspecto iconográfico. Otros aspectos quedan por ahora en lo especulativo: ¿Quiénes los hicieron? ¿Fueron los mismos canteros o los alarifes los que elegían el preciso lugar sobre el cual grabar la piedra? ¿Cuánto tiempo después de la Conquista se siguieron labrando estas serpientes que parecen recorrer algunas fachadas y muros?

Abordar un estudio comparativo entre las serpientes en altorrelieve y las supuestas serpientes "incisas" también en piedra nos proporcionaría información sobre las diferencias simbólicas entre ambas representaciones y particularmente sobre la jerarquía de sus artífices y la urgencia de su realización ante la sistemática proscripción católica de los ofidios.

Sólo un estudio físico de las piedras podría esclarecer en qué periodos de la historia de la ciudad se produjeron estos relieves y saberlo nos ayudaría a indagar por qué razón se les prefirió sobre otros seres como el felino o el ave. Parece que -como lo sugiere Luis Millones en una publicación reciente- apenas si hemos empezado a conocer el significado de la serpiente y la acepción que encarnaba en cada una de sus representaciones, entre las cuales, estos petroglifos pudieron ser la última expresión. 


\section{BIBLIOGRAFÍA}

\section{AGURTO CALVO, Santiago}

1980 Cusco. La traza urbana de la ciudad inca. Cusco: UNESCO / INC.

\section{FERNÁNDEZ BACA, Jenaro}

1989 Motivos de ornamentación de la cerámica Inca Cuzco. Tomo II. Lima: Concytec.

MILLONES, Luis et al

2012 La fauna sagrada de Huarochirí. Lima: IEP, IFEA

NÚÑ̃Z JIMÉNEZ, Antonio

1986 Petroglifos del Perú. Panorama mundial del arte rupestre. La Habana: 1986

POMA DE AYALA, Guamán

1980 El primer nueva corónica y buen gobierno. Edición de J. Murra y R. Adorno. México D. F.: Siglo XXI.

\section{RAVINES, Roger}

1986 Arte rupestre del Perú. Inventario general. Lima: Instituto Nacional de Cultura.
STASTNY, Francisco

1993 El arte de la nobleza inca y la identidad andina. En: H. Urbano (ed.), Mito y simbolismo en los andes. Cusco: Centro Bartolomé de las Casas.

\section{TUMI, Gori}

2010 "Las cuatro tradiciones del arte rupestre colonial del Cusco". En: Quellca Rumi No. 1. Lima: Asociación Peruana de Arte Rupestre.

VALCÁRCEL, Luis E

1959 Símbolos mágico-religiosos en la cultura andina. En: Revista del Museo Nacional, Tomo XXVIII. Lima: Museo Nacional.

V. AA.

1945 Cusco. Antología de los cronistas coloniales, viajeros científicos y escritores peruanos. Buenos Aires: Editorial El Ayllu (Lima). 